\title{
ULegends : Mobile Game untuk Orientasi Lokasi Kampus
}

\author{
Aji Sutrisna \\ Ilmu Komputer, \\ Universitas Pendidikan Indonesia \\ sutrisnajie@gmail.com
}

\author{
Yudi Wibisono \\ Ilmu Komputer, \\ Universitas Pendidikan Indonesia \\ yudi@upi.edu
}

\author{
Rosa Ariani Sukamto \\ Ilmu Komputer, \\ Universitas Pendidikan Indonesia \\ rosa.ariani@upi.edu
}

\begin{abstract}
ABSTRAK
Orientasi lokasi merupakan kegiatan yang bertujuan untuk mengenalkan suatu lokasi. Penelitian ini bertujuan untuk membantu kegiatan orientasi lokasi dengan penerapan gamifikasi menggunakan elemen-elemen permainan berbasis lokasi. Gamifikasi dilakukan dengan cara menjadikan materi orientasi sebagai materi permainan sehingga membuat proses orientasi menjadi lebih menyenangkan dan memberikan pengalaman baru dalam melakukan orientasi lokasi. Pengujian dilakukan oleh pengguna secara langsung dan menghasilkan respon berupa tanggapan yang dikategorikan dengan metode rating scale. Hasil analisis data respon pengguna terhadap aplikasi menghasilkan penilaian tanggapan pengguna sebesar 83\%, sehingga aplikasi permainan yang dibuat termasuk dalam kategori sangat baik dan cocok untuk membantu dalam melakukan orientasi lokasi.
\end{abstract}

Kata Kunci : Orientasi Lokasi, Gamifikasi, Permainan Berbasis Lokasi.

\section{PENDAHULUAN}

Masa orientasi mahasiswa baru merupakan salah satu kegiatan yang harus dilakukan oleh mahasiswa. Salah satu dari rangkaian masa orientasi adalah orientasi lokasi kampus. Orientasi lokasi kampus merupakan pengenalan lokasi lingkungan kampus.

Berbagai cara dapat dilakukan untuk melakukan orientasi lokasi baik cara konvesional maupun cara modern, salah satunya adalah gamifikasi dengan penerapan elemen permainan berbasis lokasi pada proses orientasi lokasi.

Gamifikasi adalah penyampaian materi konteks non-permainan (contoh belajar, pemasaran dan lain-lain) dengan mengintegrasikan elemen permainan dengan tujuan agar lebih menarik perhatian pengguna. Dalam gamifikasi penerapan elemen-elemen permainan dapat dilakukan sebagian ataupun menyeluruh sehingga berbeda dengan permainan sebenarnya (serious game) [1].

Permainan berbasis lokasi adalah permainan yang menggunakan lingkungan fisik pemain sebagai arena permainan dan mengharuskan pemain datang kesuatu lokasi untuk menyelesaikan sebuah tantangan sehingga memberikan pemain pengalaman baru dan membuat permainan menjadi lebih menyenangkan serta menarik [2] [3].

Walaupun sudah ada penelitian mengenai permainan berbasis lokasi untuk orientasi lokasi [3] [4] [5], tetapi belum ada penelitian yang menggunakan materi orientasi lokasi kampus sebagai materi permainan. Materi orientasi lokasi yang digunakan adalah foto lokasi dan informasi lokasi kampus.

Gamifikasi yang dilakukan pada materi menghasilkan permainan berbasis lokasi yang bertujuan untuk membantu proses orientasi dengan nama ULegends. Ulegends menggunakan tema fantasi sebagai dasar permainan dengan tujuan membuat permainan menjadi lebih menarik.

Makalah ini terbagi menjadi lima bagian, bagian kedua akan membahas penelitian yang terkait, bagian ketiga akan membahas permainan ULegends, bagian keempat akan membahas pengujian permainan ULegends dan bagian kelima akan membahas kesimpulan. 


\section{PENELITIAN TERKAIT}

Tujuan utama permainan berbasis lokasi adalah melakukan eksplorasi suatu lokasi dengan cara yang menyenangkan dan mengumpulkan informasi-informasi spasial suatu lokasi tertentu [6]. GeoQuest menerapkan konsep permainan berbasis lokasi dengan mengubah suatu lokasi menjadi tempat pos pemeriksaan dan pemain harus menyelesaikan tantangan yang ada di pos tersebut. Tempat pos pemeriksaan pada Geoquest menggunakan tempat-tempat bersejarah sehingga selain bermain permainan pemain juga dapat menambah wawasan[7].

Selain GeoQuest, permainan Alien Revolt juga menerapakan konsep permainan berbasis lokasi. Dalam permainan Alien Revolt pemain diminta untuk memburu alien yang tersebar di berbagai lokasi di kota, sehingga membuat pemain melakukan ekplorasi pada lokasilokasi di kota sekaligus mengenalkan lokasi tersebut[8].

Sedangkan aplikasi MEIO menerapkan konsep permainan berbasis lokasi untuk mengenalkan lokasi-lokasi di kota Brazil dengan menggunakan sistem kuis. Pemain akan diminta datang ke suatu lokasi dan diberikan pertanyaan mengenai lokasi tersebut. Dalam aplikasi ini juga terdapat peringkat dan penghargaan yang bertujuan untuk menambah motivasi pemain dalam menggunakan aplikasi [4].

\section{PERMAINAN ULEGENDS}

Permainan ULegends merupakan permainan berbasis lokasi yang mengkombinasikan gamifikasi dengan orientasi lokasi kampus. Ulegends mengunakan tema fantasi untuk menyampaikan materi orientasi pada pengguna dengan tujuan penyampaian materi menjadi lebih menarik.

Penggunaan tema fantasi membuat materi orientasi yang bersifat nyata perlu disesuaikan dengan kebutuhan permainan. Contoh penyesuaian yang dilakukan adalah penyamaran foto nyata lokasi kampus menjadi gambar lokasi permainan yang bersifat fantasi.

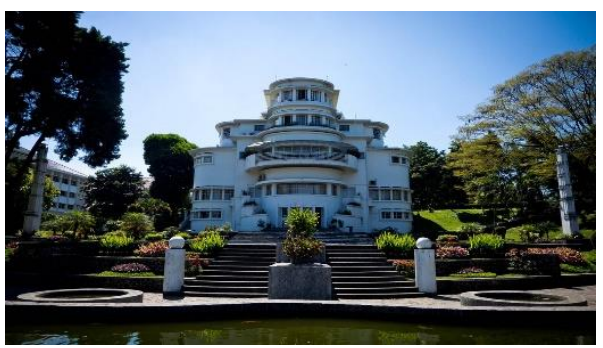

Gambar 1. Foto lokasi sebelum disamarkan.

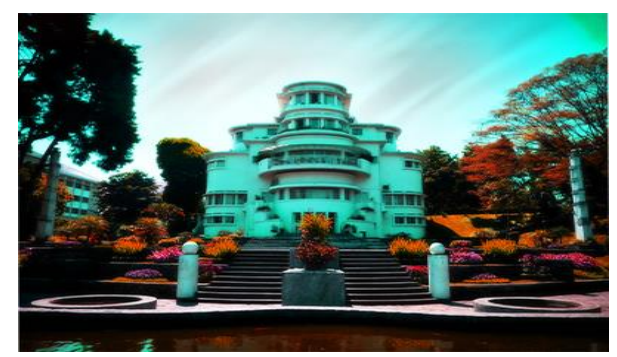

Gambar 2. Foto lokasi setelah disamarkan menjadi fantasi.

Fitur utama permainan adalah sistem quest. Quest adalah tugas yang diberikan kepada pemain sebagai tantangan yang harus diselesaikan. Sistem quest berfungsi sebagai media utama untuk penyampaian materi orientasi lokasi kampus. Terdapat empat tipe quest yang digunakan dalam permainan ULegends yaitu yaitu story, find place, find room dan battle.

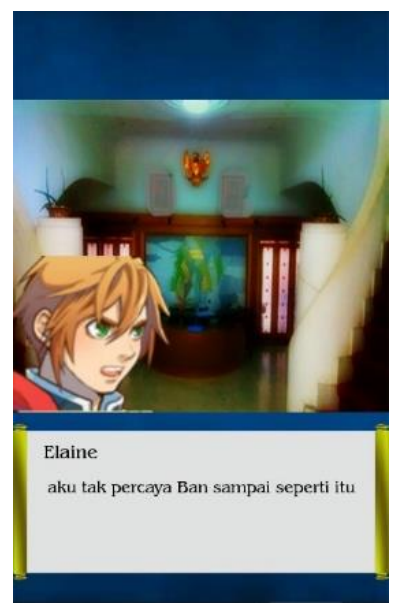

Gambar 3. Tampilan quest bertipe story.

Quest bertipe story menjadi media penyampaian informasi seperti nama dan posisi lokasi tersebut. Quest ini juga berfungsi sebagai petunjuk dalam permainan untuk memudahkan 
pemain mendatangi suatu lokasi dan penghubung antara ketiga tipe quest lainnya. Kondisi untuk menyelesaikan quest ini adalah pemain hanya perlu mengikuti cerita sampai dengan selesai dan untuk melanjutkan cerita dilakukan dengan cara men-tap layar

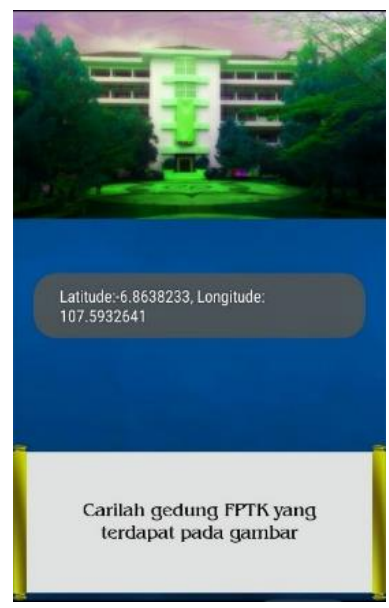

Gambar 4. Tampilan quest bertipe find place.

Quest bertipe find place merupakan quest yang meminta pemain untuk mendatangi tempat yang diminta secara langsung. Tujuan dari quest adalah memberikan pengalaman pada pemain mendatangi suatu lokasi baru. Kondisi selesai untuk quest adalah ketika posisi pemain sesuai dengan posisi tempat yang diminta. Pemeriksaan posisi dilakukan dengan membandingkan posisi pemain melalui GPS pada perangkat dengan posisi lokasi yang diatur dalam permainan.

Pemanfaatan GPS dalam quest bertipe find place memiliki kekurangan yaitu tidak efektif digunakan dalam ruangan, sehingga tidak cocok untuk mengenalkan ruangan dalam suatu gedung yang membuat proses orientasi lokasi kampus tidak bisa dilakukan secara detail. Maka dari itu, untuk mengatasi hal tersebut dibuat quest bertipe find room.

Quest bertipe find room merupakan quest yang memanfaatkan sensor kamera. Quest ini meminta pemain untuk mencari dan memindai $Q R$ code yang diletakkan disekitar lokasi yang dituju oleh permainan. Tujuan quest find room adalah membuat pemain melakukan ekplorasi secara lebih detail terhadap satu gedung yang berada pada lokasi kampus. Quest ini menggunakan materi lokasi ruangan yang ada di gedung-gedung kampus.
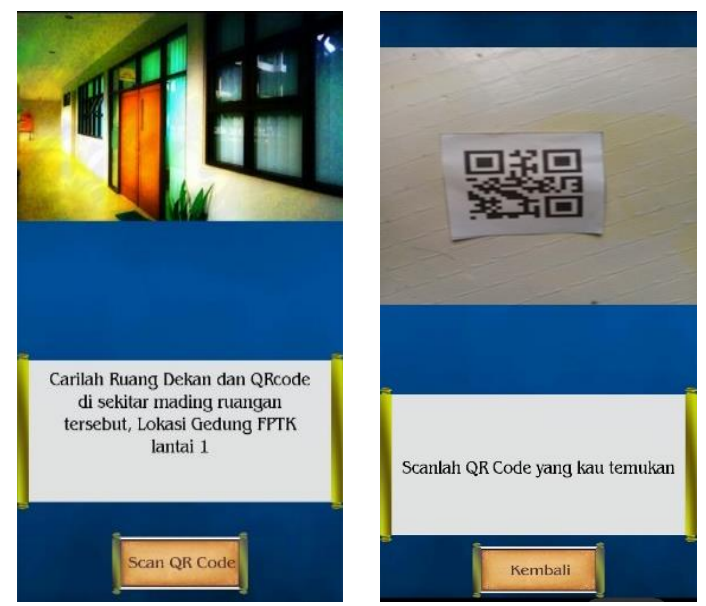

Gambar 5. Tampilan quest bertipe find room.

Untuk memindai $Q R$ code pemain hanya perlu menekan tombol scan $Q R$ code pada tampilan quest dan permainan akan menampilkan tampilan dari scene pemindaian.

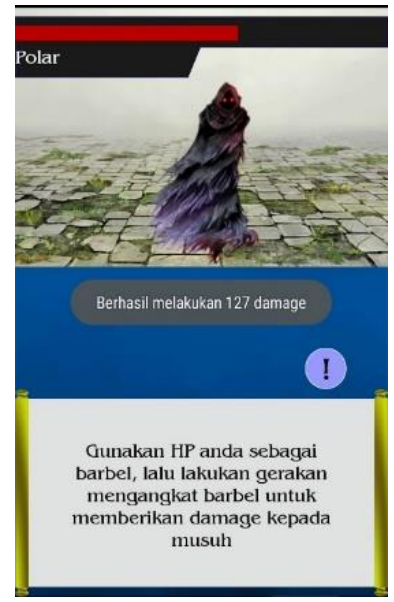

Gambar 6. Tampilan quest bertipe battle.

Quest bertipe battle merupakan quest yang memanfaatkan sensor akselerometer. Quest ini dikembangkan untuk melengkapi tema yang diangkat. Pada quest ini pemain akan diminta untuk melakukan suatu gerakan ringan seperti mengangkat barbel dan lain-lain agar dapat melakukan serangan kepada musuh. Tujuan dari quest adalah membuat pemain secara tidak langsung melakukan olahraga ringan sehingga permainan bukan hanya berfokus pada materi orientasi lokasi tetapi memberi dampak positif secara fisik pada pemain. Quest akan selesai apabila poin darah musuh habis atau 0 . Untuk 
melakukan serangan, gerakan yang dilakukan oleh pemain harus valid dan ditandai dengan munculnya getaran pada perangkat. Jumlah serangan yang diberikan pemain pada musuh akan diacak oleh sistem permainan.

Selain tampilan dari quest permainan ULegends juga memiliki beberapa tampilan lainnya seperti tampilan menu utama, tentang, daftar quest dan petunjuk dialog box. Semua tampilan dan fitur yang ada dikembangkan untuk memudahkan pemain dalam memahami dan memainkan permainan ULegends.

\section{PENGUJIAN PERMAINAN ULEGENDS}

Uji coba permainan dilakukan oleh lima responden secara langsung yang dipilih secara acak. Setelah responden melakukan uji coba dengan cara menyelesaikan semua quest yang ada, responden akan diminta untuk memberikan tanggapan berupa respon penilaian mengenai permainan yang di uji melalui kuisioner.

Aspek-aspek yang dinilai oleh responden menggunakan Learning Object Review Instrument yaitu content quality, learning goal alignment, feedback and adaptation, motivation, presentation design, interaction usability, accessbility, reusability dan standar accompliance [9].

Respon penilaian dari responden akan dianalisa menggunakan metode rating scale dengan persamaan [10].

$$
P=\frac{\text { skor hasil pengumpulan data }}{\text { skor ideal }} \times 100 \%
$$

Keterangan:

$\mathrm{P} \quad:$ angka persentase

Skor ideal : skor tertinggi tiap butir $\mathrm{x}$ jumlah butir $\mathrm{x}$ jumlah responden

Tabel 1. Kategori dengan metode rating scale

\begin{tabular}{|l|l|}
\hline Skor Persentase $(\%)$ & \multicolumn{1}{c|}{ Interpretasi } \\
\hline $\mathrm{P} \leq 20 \%$ & Sangat Kurang \\
\hline $20 \%<\mathrm{P} \leq 40 \%$ & Kurang \\
\hline $40 \%<\mathrm{P} \leq 60 \%$ & Cukup \\
\hline
\end{tabular}

\begin{tabular}{|l|l|}
\hline Skor Persentase (\%) & \multicolumn{1}{|c|}{ Interpretasi } \\
\hline $60 \%<\mathrm{P} \leq 80 \%$ & Baik \\
\hline $80 \%<\mathrm{P} \leq 100 \%$ & Sangat Baik \\
\hline
\end{tabular}

Selanjutnya tingkat validasi permainan dalam penelitian ini akan digolongkan menjadi lima kategori dengan menggunakan skala seperti pada tabel 1 .

Hasil dari kuisioner respon penilaian responden terdapat pada tabel 2 setelah dihitung menggunakan persamaan 1 .

Tabel 2. Hasil perhitungan data respon dari kuisioner responden

\begin{tabular}{|c|c|c|c|c|c|}
\hline Aspek & A & B & $\mathrm{C}$ & D & $\mathrm{E}$ \\
\hline $\begin{array}{l}\text { Content } \\
\text { Quality }\end{array}$ & 2 & 50 & 45 & $90 \%$ & $\begin{array}{c}\text { Sangat } \\
\text { Baik }\end{array}$ \\
\hline $\begin{array}{l}\text { Learning } \\
\text { Goal } \\
\text { Alignment }\end{array}$ & 2 & 50 & 39 & $78 \%$ & Baik \\
\hline $\begin{array}{l}\text { Feedback and } \\
\text { Adaptation }\end{array}$ & 2 & 50 & 38 & $76 \%$ & Baik \\
\hline Motivation & 2 & 50 & 42 & $84 \%$ & $\begin{array}{c}\text { Sangat } \\
\text { Baik }\end{array}$ \\
\hline $\begin{array}{l}\text { Presentation } \\
\text { Design }\end{array}$ & 4 & 100 & 80 & $80 \%$ & Baik \\
\hline $\begin{array}{l}\text { Interaction } \\
\text { Usability }\end{array}$ & 3 & 75 & 63 & $84 \%$ & $\begin{array}{c}\text { Sangat } \\
\text { baik }\end{array}$ \\
\hline Accessbility & 2 & 50 & 42 & $84 \%$ & $\begin{array}{c}\text { Sangat } \\
\text { Baik }\end{array}$ \\
\hline Reusability & 1 & 25 & 23 & $92 \%$ & $\begin{array}{c}\text { Sangat } \\
\text { Baik }\end{array}$ \\
\hline $\begin{array}{l}\text { Standar } \\
\text { Accompliance }\end{array}$ & 1 & 25 & 19 & $76 \%$ & Baik \\
\hline
\end{tabular}

Keterangan :
A : Jumlah butir pertanyaan
B : Nilai Ideal
C : $\quad \sum$ Skor per Aspek
D : Presentase
E : Kategori

Berdasarkan pada tabel 2 maka permainan ULegends memiliki rata-rata penilaian sebesar 83\%. Maka dapat disimpulkan bahwa respon penilaian dari responden terhadap permainan ULegends termasuk dalam kategori sangat baik.

Selain tanggapan berupa penilaian, responden juga memberikan saran terhadap permainan ULegends, yaitu: 
1. Permainan dapat digunakan dalam seluruh jenis sistem operasi Android.

2. Dalam quest find place sebaiknya dilengkap dengan fitur peta sehingga memudahkan pencarian lokasi.

3. Tampilan karakter akan lebih baik apabila ditampilkan secara menyeluruh, tidak hanya setengah badan. Tampilan secara keseluruhan dapat dikembangkan kembali.

4. Quest dalam permainan bisa diperbanyak, sehingga permainan menjadi lebih menarik dan menantang. Khususnya pada quest yang menggunakan lokasi.

Beberapa kendala ditemukan saat responden melakukan pengujian, yaitu:

1. Perbedaan akurasi GPS setiap perangkat yang menyebabkan pemain mengalami kesulitan dalam menjalankan quest bertipe find place,

2. Petunjuk lokasi yang belum terlalu detail, sehingga menyebabkan pemain kesulitan dalam menemukan lokasi yang diminta oleh permainan.

\section{KESIMPULAN}

Permainan ULegends mendapat rata-rata penilaian dari responden berupa respon sebesar $83 \%$, sehingga permainan yang dibuat termasuk dalam kategori sangat baik dan cocok untuk membantu orientasi lokasi kampus.

Untuk penelitian berikutnya, perlu ditambahkan fitur-fitur seperti mode multiplayer yang membuat permainan bisa dimainkan oleh lebih dari satu orang, kecerdasan buatan dan materi orientasi lokasi pada permainan bisa dimuat dalam genre lain karena genre fantasi kurang cocok untuk pengguna kalangan mahasiswa.

\section{REFERENSI}

[1] S. Deterding, M. Sicart, L. Nacke, K. O'Hara dan D. Dixon, "From Game Design Elements to Gamefulness: Defining "Gamification", 2008.
[2] L. Lehman, "Location-based Mobile Games," Technical University, Berlin, 2012.

[3] M.-Y. Wu, S.-R. Tsai, J.-C. Wang dan Y.C. Chuang, "A Pac-Man Game on Campus Using GPS Location Information and Shortest Path Algorithm," IEEE International Conference on Digital Game and Intelligent Toy Enchanced Learning, pp. 202-206, 2010.

[4] M. L. Santos, R. d. Souza dan M. d. C. L. da Silva, "MEIO: M-Learning, Social Network and Gamification for Enviromental Education," IEEE EATIS, 2016.

[5] D. Schuster, D. Kiefner, R. Luke, T. Springer, P. Bihler dan H. Mugge, "Step by Step vs. Catch me if u can- On the Benefit of Rounds in Location-based games," Workshopon Pervasive Collaboration and Social Networking, pp. 155-160, 2012.

[6] M. S, W. P dan M. C, "Building geospatial data collection with locationbased games," dalam in 32nd annual German conference on Advances in artificial intelligence, Germany, 2009.

[7] B. Brassai, K. Simon, B. Varga dan T. T. Vista, "GeoQuesting: Mobile Adventure Game and Web Based Game Editor," IEEE 12th International Symposium on Intellegent System and Informatics, pp. 101-103, 2014.

[8] A. D. S. Silva, "Alien Revolt (20052007): A Case Study of the First Location-Based Mobile Game in Brazil," IEEE Technology and Society Magazines, pp. 18-28, 2008.

[9] J. C. Nestbit, K. Belfer dan J. Vargo, "A Convergent participation model for evaluating of learning object," Canadian Journal of Learning and Technology, pp. 105-120, 2002.

[10] Sugiyono, Metode Penelitian Kuantitatif Kualitatif dan R\&D, Bandung: Alfabeta, 2012. 